\title{
The multisensor PHD filter: I. General solution via multitarget calculus (Erratum)
}

, "The multisensor PHD filter: I. General solution via multitarget calculus (Erratum)," Proc. SPIE 7336, Signal Processing, Sensor Fusion, and Target Recognition XVIII, 73361R (28 May 2019); doi: 10.1117/12.2539174

SPIE Event: SPIE Defense, Security, and Sensing, 2009, Orlando, Florida, United States 


\section{The multisensor PHD filter: I. General solution via multitarget calculus (Erratum)}

Ronald Mahler

Lockheed Martin MS2 Tactical Systems (United States)

Proceedings Volume 7336, Signal Processing, Sensor Fusion, and Target Recognition XVIII; 73360E (2009) https://doi.org/10.1117/12.818024

Event: SPIE Defense, Security, and Sensing, 2009, Orlando, Florida, United States

Online Publication Date: 11 May 2009

Erratum Published: 28 May 2019

The online version of the above paper was replaced on 28 May 2019 with a revision provided by the author. 